\title{
Automated Spectra Separation of Dye Mixtures
}

\author{
José Otávio Goulart PECLY ${ }^{1, \bowtie}$ and Carlos Henrique de Paula PAIVA ${ }^{2}$ \\ ${ }^{1}$ Federal University of Rio de Janeiro, PENO/COPPE, Rio de Janeiro, Brazil \\ ${ }^{2}$ Federal University of Rio de Janeiro, EQ/POLI, Rio de Janeiro, Brazil \\ $\triangle$ pecly@ufrj.br
}

\begin{abstract}
Common practices related to the use of fluorescent tracers include multiple dyes in branches of convergent streams, and multiple dyes to compare the performance and to control the quality of the results. Although the control software of spectrofluorometers presents advanced features like multiple peak identification, a spectral separation function is usually not available. It is worth to note that a typical field campaign may result hundred or even a few thousand of samples whose tracers need to be identified and have its concentration measured. To deal with this issue, a set of Python scripts for background subtraction and spectra separation was tested with a dataset of samples with a single tracer and with mixtures of Eosin and Fluorescein. The uncertainty of the results is dependent on the concentration ratio of the tracers in the sample.
\end{abstract}

Keywords: fluorescence, spectral characteristic, separation method.

\section{INTRODUCTION}

Field campaigns employing fluorescent tracers provide data to estimate hydraulic parameters or to calibrate water quality models (Romanowicz et al. 2013).

As the spectra of tracers considered safe (Behrens et al. 2001) for application in inland, estuarine, and coastal water bodies present full width at half maximum (FWHM) relatively wide, the analysis of samples with mixture of tracers requires special attention (Käss 1967). 


\section{MIXTURE SEPARATION METHOD}

Typical concentrations in field works are small, ranging from 1 to $20 \mathrm{mg} \mathrm{m}^{-3}$ at the sampling sites. These low concentrations, usually quantified by spectrofluorometers, present issues related to peak identification and separation by the instrument companion software or visual spectra inspection (see Fig. 1).

\subsection{The experimental dataset}

Laboratory work started with the preparation of standard solutions with concentrations of 1, 2, 5, 10, and $20 \mathrm{mg} \mathrm{m}^{-3}$ of Eosin and of Fluorescein followed by mixtures of these standards in destillated water. Sample analysis was carried out by the synchronous scanning method.

\subsection{Spectra separation}

A set of Python functions was built for adjusting Lorentz curves to the measured spectra for each selected tracer which is individually defined by a peak wavelength and by a FWHM.

The application used the least square fitting of the scipy.optimize.curve_fit function. Figure 1 depicts the result of the spectra separation for one sample with a mixture of $2 \mathrm{mg} \mathrm{m}^{-3}$ of Fluorescein with $20 \mathrm{mg} \mathrm{m}^{-3}$ of Eosin. The differences between the concentrations of the standard samples and those obtained from the adjusted spectrum were 19\% for Fluorescein and 1.5\% for Eosin, decreasing to $3.5 \%$ and $0.5 \%$, respectively, after the application of the method.
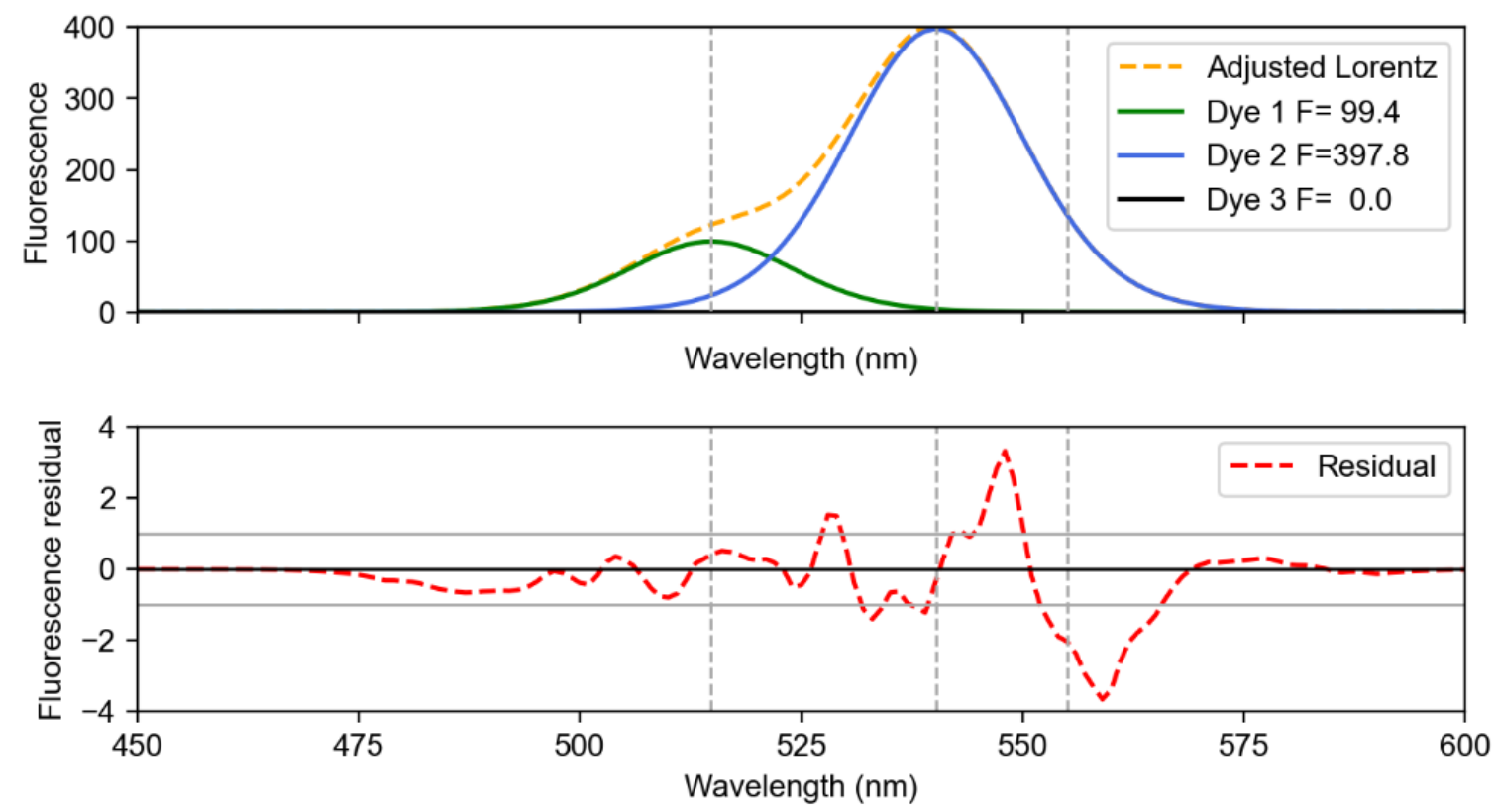

Fig. 1. Spectra of a sample with mixture of tracers: (above) adjusted spectrum by the sum of individual spectra; and (below) difference between the adjusted and the measured spectra.

The differences between the concentrations obtained from the adjusted spectra of samples with a single tracer and the mixture were $1.5 \%$ for Fluorescein and $1.0 \%$ for Eosin. For higher concentration ratios, e.g. a mixture of $20 \mathrm{mg} \mathrm{m}^{-3}$ of Fluorescein with $2 \mathrm{mg} \mathrm{m}^{-3}$ of Eosin, the differences between the concentrations of Eosin obtained from the adjusted spectrum were $100 \%$ and $6 \%$, before and after the application of the separation method, respectively.

Acknowledgments. The second author acknowledges Fundação COPPETEC for the grants received along the development of this work. 


\section{References}

Behrens, H., U. Beims H. Dieter, G. Dietze, T. Eikmann, T. Grummt, H. Hanisch, H. Henseling, W. Käss, H. Kerndorff, C. Leibundgut, U. Müller-Wegener, I. Rönnefahrt, B. Scharenberg, R. Schleyer, W. Schloz, and F. Tilkes (2001), Toxicological and ecotoxicological assessment of water tracers, Hydrogeol. J. 9, 3, 321-325, DOI: 10.1007/s100400100126.

Käss, W. (1967), Erfahrungen mit Uranin bei Färbversuchen, Steirische Beitr. Hydrogeol. 1966/67, 123-134.

Romanowicz, R.J., M. Osuch, and S. Wallis (2013), Modelling of solute transport in rivers under different flow rates: A case study without transient storage, Acta Geophys. 61, 1, 98-125, DOI: 10.2478/s11600-012-0050-8.

Received 22 March 2021

Accepted 12 April 2021 